International Journal of Instruction e-ISSN: 1308-1470 • www.e-iji.net

Article submission code: 20200821200925

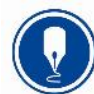

October $2021 \bullet$ Vol.14, No.4

p-ISSN: 1694-609X

pp. 607-626

Received: 21/08/2020

Revision: 08/04/2021
Accepted: 02/05/2021

OnlineFirst: 23/08/2021

\title{
Does the Flipped Classroom Boost Student Science Learning and Satisfaction? A Pilot Study from the UAE
}

\section{Zuhrieh Shana}

Dr., Al Ain University, Abu Dhabi, United Arab Emirates, zoeshanaa@yahoo.com

\section{Suad Alwaely}

Prof., Al Ain University, Abu Dhabi, United Arab Emirates, suad.alwaely@aau.ac.ae

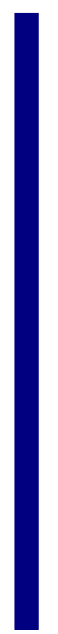

This study investigated the impact of the flipped classroom on grade six students' academic achievements and perceptions in science class. Participants $(n=39)$ were assigned to a control group (using traditional instruction) or an experimental group (using flipped instruction). Data analysis was done using Statistical Package for the Social Sciences (SPSS). Pre-test scores of both groups were compared by using independent $t$-test. The obtained " $\mathrm{t}$ " value of 1.22 was found to be insignificant at $\mathrm{p}=0.229(>0.05)$ which revealed no significant difference between these groups at the beginning. After three weeks, their post-test scores in science were again compared to examine the impact of different instructional interventions. The obtained " $\mathrm{t}$ " value of both groups' post-test score comparison was 2.646 which was found to be significant at $\mathrm{p}=0.012(<0.05)$. Likert Scale Questionnaire was also employed to explore if students had valued the experimental intervention. It was revealed that the students were highly satisfied with the flipped classroom. This confirmed the difference between the control and experimental groups. Mean scores of flipped and traditional instruction groups further assured that flipped instruction had an impact on students' learning performance and perceptions.

Keywords: flipped classroom, students' achievement, technology-supported learning, flipped learning, science, middle school

\section{INTRODUCTION}

\section{Background of the Study \& Research Problem}

Although there is no universally accepted definition of flipped classroom, the core idea is "to shift learning by transmitting information to before class, in the form of instructional videos, recorded lectures and other remotely-accessible pedagogical resources" (Goedhart, Westrhenen, Moser \& Zweekhorst, 2019). Therefore, the flipped classroom can be defined as "Inverting the classroom means that events that have traditionally taken place inside the classroom now take place outside the classroom and vice versa." (Lage, Platt, \& Treglia, 2000). Generally, a wide array of definitions on flipped classroom can be observed in recent literature (Abeysekera and Dawson, 2015).

Citation: Shana, Z., \& Alwaely, S. (2021). Does the flipped classroom boost student science learning and satisfaction? A pilot study from the UAE. International Journal of Instruction, 14(4), 607-626. https://doi.org/10.29333/iji.2021.14435a 
Specifically, for this study, the Bergman and Sams (2012) definition was adopted. Bergman and Sams defined flipped learning/classroom as what is usually done in class is done at home and what is done at home is done in class. Consequently, according to this definition, the flipped classroom model consists of two main components. These components are defined as "Out of class implementations" and "In class education activities" (Kara, 2016).

Accordingly, in the out of class learning component, students learn the course materials by watching instructional videos (Hew and Lo, 2018). Although teachers can provide guidance and ensure students have adequately prepared for class meetings (Clark 2015), doing so allows class time to be dedicated to cultivating learners' higher-order thinking skills and to devote their time and effort in more significant actions, Teachers can give more time to coaching their students and helping them with inspiring projects that give them a better understanding and more control over their learning. (Strayer, 2007). Accordingly, in flipped classroom, the teacher still is central to the learning, but assumes a facilitator role of student learning and are the creators of productive classroom environments (figure 1). This can help learners improve learning and develop skills that can help move them from where they are now to where the teacher thinks they should be.

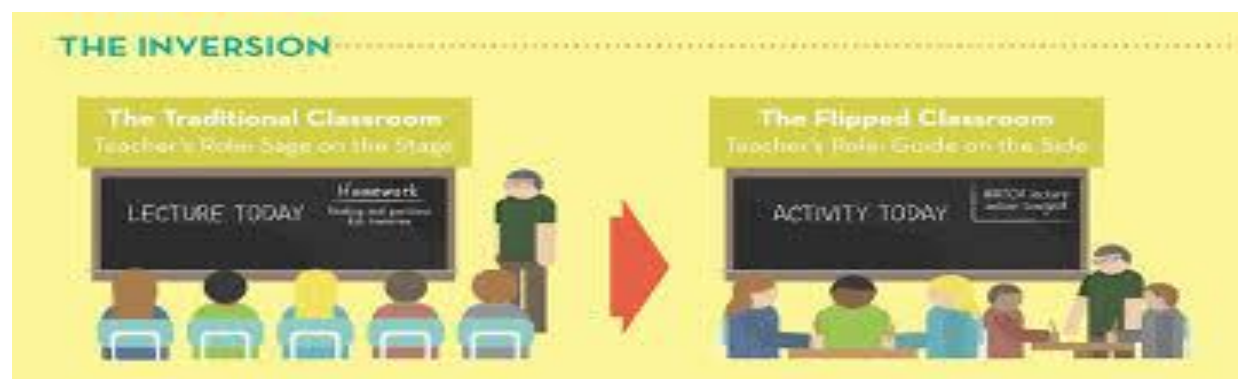

Figure 1

Flipped classroom versus traditional lecture

Source: http://www.knewton.com/blog/education-infographics/flipped-classroominfographic

As for the in-class learning component, students are encouraged to deepen their understanding and increase their knowledge and skills by applying the instructional material during class in problem-solving assignments (Bergmann \& Sams, 2012).

The concept of a flipped classroom is not new in education, however in the past few years, flipped learning has become increasingly popular in education. This method has taken on an even more suitable name, as "Flipped Learning", where emphasis is put on the education aspect. According to Ayçiçek \& Yanpar Yelken (2018), in flipped classroom, the teacher takes the role of a mentor. This factor can change the teachinglearning process and make it more independent as stated by Girmen \& Kaya "By changing teaching-learning process, the students moved out to an independent learning environment, without time and space limit" (2019). 
Flipped learning came about in the 2000s when it was spread and recommended by chemistry teachers Jon Bergman and Aaron Sams (Bergmann and Sams, 2012) and Salman Khan, the Khan Academy's founder (Khan, 2011). It is a technique where the students are introduced to the learning material before class. Accordingly, this practice will ensure that students know what they should ask about during the class period. Thus, classroom time will be used to enhance their understanding through conversation, elaboration and discussion with peers and problem-solving actions facilitated by teachers (Strayer, 2007). A spotlight has been placed on the utilization of Bloom's scientific classification as opposed to the generation and appropriation of recordings. Nevertheless, whether a flipped learning condition works as far as increasing student commitment and results, or if flipped learning is taking in another instructing trend that will soon observe a misfortune in build-up, are questions that still have to be answered.

Additionally, research has shown that student-centred teaching methods such as active and technology-rich methods have advanced through the previous decades to change the way students learn new material (Shana, 2009). The learning model known as the flipped classroom is one where instruction encourages contemplation. In the flipped classroom, students are given beginning data outside of the classroom and utilize class time to formulate their insight base (Bishop \& Verleger, 2013).

Furthermore, the flipped classroom has numerous advantages, as specified by Ryan and Reid (2015); for example, helping struggling learners to watch recordings a few times, and improving the cooperation amongst learners and educators, which provides a healthy learning environment, where learners can learn at their own specific pace and empower the connection among themselves and increase information exchange.

Yet, after reviewing the literature related to flipped classroom, it was found that there is a clear general shortage in number of qualitative and quantitative studies regarding the impacts of flipped classroom on the students' academic achievements, teaching processes, and learning processes. This shortage is most severe in developing countries. In addition, the review of literature evidenced inconsistent findings regarding the effects of flipped classroom on academic achievements, with some suggesting significant benefits while others reporting slight improvement over traditional teaching methods.

\section{Statement of the Problem \& Research Question}

For students to be able to learn science effectively, the most current technology in teaching is needed. This is attributed to the fact that science is considered a complex and interactive subject that requires interaction between students and teachers. The adoption of the flipped classroom has played an imperative role in ensuring that students can learn science outside of the school and watch science videos and power point presentations that have been organized by teachers or instructors. In the classroom, the instructors can focus on enhancing students understanding of the subject. Instructors also use class time to enforce collaborative learning among students as well as offering student-centered practices.

Some scholars like Strayer (2007) carried out research on the influence of flipped classrooms on the learning of English and science. The study found that the flipped 
classroom has a significant impact on students' performance. In addition, a study by Elian \& Hamaidi (2018) investigated the impact of flipped instruction on the academic achievement on fourth-grade students and found that it resulted in a marked positive improvement in their scores. The current study aims to assess the influence of flipped and traditional teaching on the performance of sixth-grade students in science.

The current study seeks to answer the following two research questions:

- What is the impact of flipped instruction on student achievement in a sixth-grade science classroom?

- What are students' perceptions of the flipped instruction in a sixth-grade science classroom?

Research Sub-Questions:

- Do the pre-test scores for the experimental group and the control group show significant differences at the starting point of the study?

- Does overall science knowledge and skill increase, from the pre-test to the posttest, among the experimental group and the control group?

Therefore, the objective of this study is to compare the impact of flipped mode and traditional mode of instruction on the learning outcomes of sixth-graders in science. It also investigates the students' opinions about the methodology as well as their views on its value in affecting their achievement and interest in science.

\section{Literature Review}

Due to the newness of the flipped teaching/learning method on the one hand, and the distinct importance of the variable of academic accomplishment on the other hand, various educational theories and numerous studies have been done in this field nationally and internationally. Previous literature shows that flipped classroom strategy was studied in different contexts. Therefore, this literature review provides an overview of current knowledge, relevant theories, methods, and gaps in the previous research regarding flipped classroom. Vygotsky's social constructivism theory, Bandura's Social Learning Theory and Bloom's Taxonomy are covered.

\section{An Overview of Flipped Classroom}

In describing the notion of a flipped classroom, Wolff \& Chan (2016), specified that the teacher already provides resources (such as documents, audio, video) based on educational content. These resources are made available to students outside the classroom. To best support the students' learning, the teacher sets up an in-classroom homework assignment based on the educational resources earlier seen by the students at home, to give the students chance to practice and strengthen their learning in the classroom. Actually, because of this flipped process that occurs in swapping homework for class work, they are referred to as the flipped class. 
With respect to the effect of using the flipped classroom strategy on the academic achievement in the subject of science, Quint (2015) analyzed the sufficiency of the flipped classroom in a school science class. This examination discussed the gap of the flipped classroom in its significance to control get-togethers to evaluate the practicality of the flipped classroom. The revelations uncovered that flipped classroom instruction built up students' reasoning. In addition, the findings showed that the repeated use of the flipped classroom was effective in creating growth in the measures of learners' output compared with classes treated traditionally.

Moreover, flipped learning is individualized learning. In the flipped classroom, educators are executing distinct guidelines, issue/venture-based education and requestbased investigation. Flipped learning is in a general sense student-driven (Schultz, Duffield, Rasmussen \& Wageman, 2014). The flipped approach developed in 2006 and utilizes screen-casting to convey direction that can be acquired anytime, anywhere. The flipped classroom is not an equivalent word for online recordings; it is the cooperation and the essential learning exercises that happen during the students' personal time. It is a domain where learners assume responsibility for their learning, are engaged with the knowledge they are gathering, and receive customized instruction (Schultz et al., 2014).

The flipped classroom is versatile to educators' styles, strategies, and conditions; instructors can customize their variant of flipped learning for their students and play to their qualities as instructors (O'Flaherty \& Phillips, 2015). In advanced education, teachers have started to move parts of their substance conveyance outside of the classroom. In this way, time spent at the school is dedicated to advanced investigation. Students have positive input about the experience. Flipped learning profoundly affects the expertise of educators; however, more significantly, it emphatically influences the lives of students (Jungić, Kaur, Mulholland \& Xin, 2015).

According to (Hung, 2017), effective flipped learning conditions are comprised of various parts. The primary segment is cooperation since it is hard to ensure flipped adaptive learning alone. In spite of the fact that the flipped classroom may seem disordered, uproarious, or even untidy, the joint effort occurring in the flipped classroom helps in student learning. The second condition is student-focused learning since the flipped classroom moves from current instructor practices such as presentations and lectures, to student-centered learning in which an educator is a facilitator of learning. The third segment is renovated learning spaces so that in flipped classrooms educators are not the core focus. Whiteboards, LCD projectors, and recordings ought to be the focal point of consideration of the class for greater commitment from students and dynamism. Satisfactory time for usage of practices is the fourth segment in which a lot of time is required to actualize the different exercises that flipped classroom involves. The fifth part is the need for help from heads in charge of the school. Executing the flipped classroom consists of the collaboration of different educators and principals to give proficient advancement and assets to make the flipped classroom useful. Finally, the offices in colleges should offer access to recordings and sites to allow for flipped classroom instruction (Jungić et al., 2015). Cabi (2018) found that students had positive attitudes towards the instruction, but that they needed more 
instruction and guidance about how many hours should be spent on learning outside the classroom, and what activities should be undertaken during their hours of study.

\section{Vygotsky, Bandura, and Bloom's theories}

The utilization of the flipped classroom mode of instruction can be directed by the constructivism hypothesis when teaching new ideas. This is important since this investigation might lead to the application of the flipped classroom strategy in teaching new aptitudes, which require more communication among students, to share their insights and abilities with each other. The Vygotsky and Bandura's hypotheses were used to clarify the connection between the flipped classroom direction and scholarly accomplishment in new aptitudes. Bloom's Taxonomy thinking levels are apparent in the flipped classroom strategy since class time is spared for practicing the higher thinking skills, keeping the lower thinking abilities to be used at home for video learning.

Vygotsky prescribed that students acquired information through social association with others by supporting them to display their learning and giving them reasonable practice exercises. This framework of learning is demonstrated by flipped classroom learning; facilitators utilize the class time to expand the level of problem solving and to enhance the student's reasoning aptitudes. The educator's role ought to be as a facilitator of the learning procedure by utilizing demonstration and framework procedures (Schreiber \& Valle, 2013). This framework procedure is executed in the flipped classroom guideline in every exercise, since the instructor is giving students metacognitive help, to guarantee that students are in charge of their learning (Schreiber \& Valle, 2013). When Vygotsky's social constructivism hypothesis is put in practice as part of learning in the science classroom, the instructor is a facilitator and innovation is used adequately in learning.

Additionally, research has shown that Bandura's Social Learning Theory gave another hypothetical system to the utilization of the flipped classroom guideline in instructing. Social learning hypothesis demonstrates the capability of the ecological and psychological component interfaces to shape learning and conduct. Students can gain from each other, by displaying and watching (McLeod, 2011). By watching a model, students are required to learn complex new abilities rapidly.

Bloom's scientific classification, meanwhile, is an instructional structure that is regularly used to decide the results of educating and learning (Pierce \& Fox, 2012). Bloom's scientific categorization has six levels: recollecting, downplaying, applying, examining, assessing and making. Making is the most elevated level of the psychological area. The most elevated three levels of Bloom's scientific classification (breaking down, evaluating and making) are known as higher-order-thinking skills (HOTS). At the point when educator-focused learning is prevailing, instructors practice excessive control over their students, with the outcome that students tend to learn actualities as opposed to profound ideas, so education does not go past the three lower levels of Bloom's scientific categorization.

In the flipped classroom, the constructivist hypothesis is clear since students take on their learning duties, so Bloom's scientific classification is flipped around (figure 2). 
Students need to work on recollecting, downplaying and applying at home through watching videos, going to course-related sites, tuning in to soundtracks, or if nothing else, perusing the exercise. In class, instructors help students with breaking down, assessing and synthesizing the information that has been given. In this manner, educators invest sufficient class energy with students as they take part in exercises that require upper-level abilities of Bloom's scientific categorization, which encourage further learning.

Traditional Model

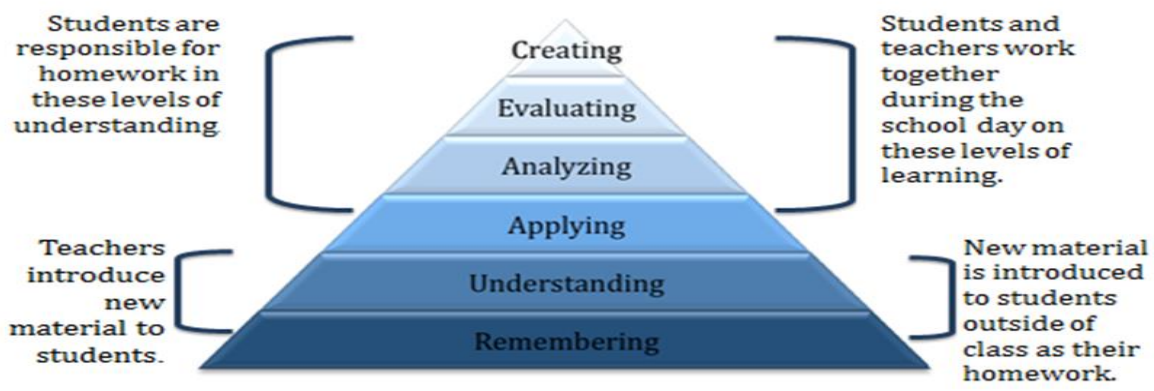

\section{Blooms Taxonomy}

Figure 2

Bloom's taxonomy in flipped classroom (Williams, 2013)

According to the mentioned facts and theories, flipped classroom has the potential to allow struggling learners with more opportunities to understand and comprehend a topic prior to class, and therefore offers more chances to interact and participate (Hamdan, McKnight, McKnight and Arfstrom, 2013). This fact has been supported by several other studies. One such study is done by National Center for Case Study Teaching in Science (NCCSTS) which has more than 15,000 members in the fields of science, technology, engineering and math. Based on the views of 200 educators, who use a flipped classroom model, the advantages include the following (Herreid and Schiller, 2013; 62):

- It provides more one-to-one time between teacher and student and more collaboration time for students.

- It encourages students to come to class prepared, which will make it easy to follow the class.

- It provides reinforcement to the students' thinking inside and outside classroom time. This will make the subject matter and content richer.

International Journal of Instruction, October $2021 \bullet$ Vol.14, No.4 
- Students will be more active in the learning process and can learn at their own pace.

- Students will be actively engaged in the learning environment and material, which will help them love the work they do.

On the other hand, some argue flipped learning technology in the classroom can cause serious problems to students' learning processes. Students may be stressed with the amount of responsibility they would have to hold in this environment (Phillips \& Trainor, 2014). In support of this fact, a study conducted by Miller (2012) and Duerden (2013), done to investigate benefits and disadvantages of a flipped classroom, concluded that benefits and challenges co-exist in a flipped classroom, and while the advantages are noticeable, the disadvantages are unavoidable. According to the generated results of the above-mentioned studies, the disadvantages include the following:

- Teachers often struggle with knowing whether the students watch the videos or not.

- Students who have a learning difficulty face trouble in this educational setting. The learners need to know what to do if their internet breaks down or if they have no access to the internet.

- Technology requirements can contribute to increasing costs and difficulty in learning if there is no internet connection or computer.

- It includes a heavy reliance on student motivation. Making your students interested and motivated in a subject can be a real challenge.

With regards to the effect of a science-centric flipped classroom on achievements, a recent study done by Elian and Hamaidi (2018) aimed to examine the effect of the flipped classroom strategy on the learning achievements within the subject of science among fourth grade students in Jordan. The study sample (44) was divided into two equal groups: the experimental group and control group. Data generated from both groups was collected, analyzed and evaluated. The results showed that students taught by means of the flipped classroom method perform better than those taught using the traditional method. Furthermore, there were no statistically significant differences in achievement scores based on gender. The study findings encouraged teachers of science to teach students by using student-centred, technology-based strategies - in particular, the flipped classroom strategy.

Furthermore, in current literature, numerous studies have investigated the effect of the flipped classroom experience on student's perception. In general, the majority of student responses to the flipped classroom were largely positive (Bishop and Verleger, 2013); most students had a positive and encouraging experience and expressed overall satisfaction in a flipped classroom (Schrlau, Stevens, \& Schley, 2016; Gecer \& Gag, 2012; Phillips \& Trainor, 2014), with a significant minority being opposed (Lage et al. 
2000). The study of (Chuang, Weng, \& Chen, 2018) also affirms that flipped classroom does not fit all students.

Technology provides different opportunities to make learning more fun and enjoyable for some. Consequently, students feel more engaged and motivated in this type of learning environment and would likely take another flipped course in the future (McCallum, Schultz, Sellke, \& Spartz, 2015). The above-mentioned benefits of flipped classroom can help create the best chance of providing a well-perceived learning experience for students.

After reviewing the previous studies, the researchers did not find any national study that explores the effect of flipped classroom strategy on grade six students' academic achievement of science, which necessitated executing this research study. Therefore, this study attempts to fill this gap in related literature by identifying the impact of using flipped classroom strategy on scientific achievement/attitude among six graders in UAE local schools.

\section{METHOD}

This methodology includes the research design, target population, sample size, research instrument and data analysis.

\section{Research Design}

This study adopted a quantitative quasi-experimental design to investigate the effect of using flipped classroom instruction in teaching sixth-grade science skills. Two classes of six-grade science were purposely selected to participate in this study. Each class was assigned randomly to either the experimental or the control group as followed:

1. The experimental/instructional intervention group - Class 6B: Students taught science skills using the flipped classroom instruction $(\mathrm{N}=25)$

2. The control group - Class 6G: Students taught science skills using the conventional/traditional teaching methods $(\mathrm{N}=14)$.

Both groups were tested their first test (pre-test) on the $4^{\text {th }}$ week of the second semester of 2018, prior to the flipped classroom intervention, and a final (post-test) on the $8^{\text {th }}$ week after the intervention.

The science pre-test was given to the two groups to test the uniformity between them before starting the study. After three weeks, the post-test was given to the two groups, in order to compare their achievements after the implementation of the flipped classroom instruction. Data generated from statistically analyzing the mean scores of pre-test and post-test were used to answer the sub-questions.

Consequently, the result of comparing the mean scores for the pre-test and the post-test will be evidence on the impact of the intervention/flipped instruction on participants' academic achievements, thus answering the main research question, "What is the impact of the flipped instruction on student achievement in a sixth-grade science classroom?" 


\section{Target Population}

The purpose of this study was to evaluate the overall effect of flipped learning on students' academic attainment in grade-six science in a private school in Abu Dhabi. The conveniently selected school is the International Academic School in Abu Dhabi. The school was selected because of its geographical location, which can be easily accessed, and its willingness to cooperate and participate in this study.

Thus, the data were drawn from two grade six classes from the selected school. Classes were chosen because they study the same exact content by the same teacher, who agreed to participate in this study. Selected students were those who agreed willingly to participate in this study. Therefore, a total of 39 (14 female and 25 male) participants were purposely drawn from the selected classes $(6 \mathrm{~B}$ and $6 \mathrm{G})$ in the designated school. Selected classes were assigned randomly to either the control (traditional instruction) or the experimental (flipped instruction) group.

Accordingly, the sample of this study ( $\mathrm{N}=39)$ consists of sixth-grade students, with class (6B) students forming the experimental group $(\mathrm{N}=25)$, while class $(6 \mathrm{G})$ students form the control group $(\mathrm{N}=14)$.

With respect the experimental group's intervention, flipped instruction was used in which students were given diverse materials such as video lessons and reading materials, before the usual class, to be reviewed at home. While, the control group was taught using the same traditional teaching/conventional method.

\section{Research Instrument}

To evaluate the impact of flipped instructions on grade six students' performance and perspective in science, the study adopts a pre- and post-test and student survey (Likert scale).

This study is a pre-post-test quasi experimental one. The study groups were tested before conducting the experimental intervention (pre-test). Participants were test again (post-tested) at the end of intervention. The purpose of these tests was to evaluate the students' comprehension of the main concepts and ability to understand or perform the required scientific competencies. In addition, a student survey included nine questions around the attitudinal aspect of the students' experience in using the flipped class learning method to support face-to-face accomplishments. The tests and survey were evaluated and validated by an AAU's panel of experts. Their comments, advice and recommendations were taken into consideration. Consequently, tests and survey were edited and modified.

The same teacher taught both the experimental and control groups' classes. This fact should help ruling out any effects caused by a teacher on a course taught by two different teachers. The tests were teacher-made, paper and pencil. The teacher is experienced and certified in teaching Science. Therefore, a pool of reliable questions 
was available through an item analysis at the end of the term, and after the deletion of questions missed by top-level students.

To ensure the content validity, and based on Popham (2014) who defines content validity as "the extent to which an assessment procedure adequately represents the content of the curricular aim being measured" (P.103). Therefore, the pre-test and posttest and Likert scale questions' validity were ensured by preparing the questions to best match the stated targeted objective that should be attained by the end of the quasiexperimental research.

The pre-test and post-tests were developed to assess the participants' science knowledge and skills. Establishing a test's content validity involves examining the questions and making a judgment regarding the degree to which the test reflects the required science knowledge or skills. For this reason, 14 experienced science educators and supervisors from different local schools, as well as an experienced group of science teachers from the same school, reviewed the test content. Tests items were modified according to their comments and recommendations. Then modified tests were presented again to the same experts till all of them ensured that the tests were well-prepared, and it covers and measured what it was intended to measure as per stated objectives. This fact can be considered as evidence of tests/questions validity.

Furthermore, to investigate the students' perceptions of their achievement due to the implementation of flipped classroom, a three-point Likert scale was used to obtain students' responses. The experimental group participants were asked to respond to a survey of nine questions with: agree, neutral, or disagree. Using the three-point Likert scale survey, students were asked to respond to statements that measured their perceptions of the effect of flipped classroom on their learning, as shown in table 1. 
Table 1

Agreement with statements about how the flipped classroom activities supported academic achievement.

\begin{tabular}{|c|c|c|c|c|}
\hline \# & Statements/Questions & Agree & Neutral & Disagree \\
\hline \multicolumn{2}{|r|}{ The flipped lessons helped me in the followings: } & $\%$ & $\%$ & $\%$ \\
\hline 1 & The out of class reading helped me understand the lesson better. & 90 & 5 & 5 \\
\hline 2 & $\begin{array}{l}\text { Appreciating flipped instruction learning method more than } \\
\text { traditional instruction. }\end{array}$ & 85 & 10 & 5 \\
\hline 3 & $\begin{array}{l}\text { Developing more positive attitudes towards learning in the } \\
\text { classroom. }\end{array}$ & 95 & 5 & 0 \\
\hline 4 & Making the teaching/learning process more engaging. & 90 & 5 & 5 \\
\hline 5 & Grasping science concepts better through watching video. & 95 & 0 & 5 \\
\hline 6 & Making the learning process easier and more motivating. & 100 & 0 & 0 \\
\hline 7 & $\begin{array}{l}\text { Giving more opportunities in communicating with others than } \\
\text { traditional method. }\end{array}$ & 90 & 10 & 0 \\
\hline 8 & $\begin{array}{l}\text { Facilitating my interaction with content rather than listening to } \\
\text { the teacher. }\end{array}$ & 85 & 10 & 5 \\
\hline 9 & Making the learning process more fun and meaningful. & 95 & 5 & 0 \\
\hline & $\begin{array}{l}\text { average percentage of students' responses to the three-point Likert } \\
\text { statements. }\end{array}$ & 91.6 & 6.1 & 2.7 \\
\hline
\end{tabular}

The survey was given to the experimental group participants after the post-test on the 10th week of the academic term. The results are presented in the form of tables, charts and figures. Data analysis was restricted to the participants who continued in the study and didn't miss any class activity and took their tests on the scheduled date. A total of 2 students were excluded primarily because they were absent on the days of the tests.

\section{FINDINGS}

Since research is purely a scientific, methodical way to find answers to questions used to discover new information or confirm facts and logical theories, the data analysis for each research question will be addressed separately and combined, and should yield detailed findings that evidently answer the research question(s). The research questions are as follows:

1-What is the impact of the flipped instruction on student achievement in a sixthgrade science classroom?

For the purpose of answering the first research question, the pre-test scores of both groups were compared through independent - $t$ test. The obtained " $t$ " value of 1.22 was 
found to be insignificant at $\mathrm{p}=0.229(>0.05)$ which revealed no significant difference between these groups at the beginning. Thus, both groups were assumed to have the same academic background. After three weeks, their post-test scores in science were compared to inspect the effect of the various instructional interventions. The obtained “' $t$ " value of both groups' post-test scores comparison was 2.646 which was found to be significant at $\mathrm{p}=0.012(<0.05)$ as shown in table 2 . This assured the difference between the research groups. Mean scores of flipped and traditional instruction groups further strengthened the positive impact of flipped mode of instruction on students' learning outcomes in science.

Table 2

Descriptive statistics of student achievement, independent t-test results, and effect sizes

\begin{tabular}{llllllll}
\hline \multirow{2}{*}{ Test } & Flipped & \multicolumn{3}{c}{ Traditional } & T & Sig. & $\begin{array}{c}\text { Effect Size } \\
\text { Cohen's d }\end{array}$ \\
\cline { 2 - 6 } & Mean & Std. Dev. & Mean & Std. Dev. & & \\
\hline Pre-Test & 27.72 & 9.12 & 31.71 & 10.93 & 1.22 & 0.229 & 0.46 \\
\hline Post Test & 41.6 & 9.43 & 32 & 13.12 & 2.646 & $0.012^{*}$ & 0.84 \\
\hline
\end{tabular}

This flipped classroom intervention helped students acquire access to dynamic learning, prompting the high accomplishment of students who connected with the flipped classroom learning, in contrast to the individuals who were subjected to the traditional classroom learning.

The outcomes demonstrated the students' inspirational states of mind towards this system. Students relayed the most useful qualities of this methodology, for example, that they could watch the videos a few times until they fully understood the material and that they ended up in charge of their own learning.

Based on the findings from the current study, students held positive views of the flipped instruction method, which may have contributed to even greater improvements in their performance. Scores of students placed in flipped classrooms were higher than those placed in traditional classes.

In general, the results of the Likert scale indicated consistency with the research of Eryilmaz and Cigdemoglu (2019), Nam (2019), and Wang and Zhu (2019)). All the mentioned studies assured a positive effect of the flipped classroom on learners' attitude.

\section{2-What are students' perceptions of the flipped instruction in a sixth-grade science classroom?}

In answering the above research question, data generated from the Likert scale survey regarding their experience with flipped classroom is used to first answer the following sub-question:

Do participants prefer the flipped classroom approach more than the traditional way of teaching? 
The results show that most of the research participants indicated that they agree on almost all questions (see table 2). This suggests that students are satisfied with the flipped classroom strategy.

Attitudes changed after using the flipped classroom. Positive changes were reported in this study; participants reported high level of enjoyment, increased involvement and decreased boredom, and greater task value in flipped classroom.

The findings also showed that most students believe that their attitude towards learning science is positive. This has been attributed to the fact that they have adopted a new learning method; the change in attitude led to improved performance in this subject (Shana \& Abdalbaki, 2020). Those who indicated that they disagreed about their change in attitude most probably did not perform well. The study also revealed that most respondents like to interact with content rather than listening to the teacher and memorizing the content. Furthermore, the study found that most students agreed that out of class discussion of the assigned reading materials is essential. They revealed that improved performance is attributed to the fact that they can freely discuss the details of the study material with their classmates. The Likert scale survey also revealed that most students agreed that watching educational videos positively impacted their performance. Furthermore, participants approved that the average time spent watching videos was helpful to them in understanding sciences concepts and ideas. The study also found that the majority of respondents indicated it is essential to have time working with their colleagues. They stated this has enhanced their performance.

Based on the findings, most students believe that flipped classroom instruction helped them learn science and is the more effective, easy, motivating, meaningful, fun and engaging method of learning, as compared to the traditional method of instruction. The respondents also agreed with the statement that they prefer flipped instruction learning over the traditional teaching method. A detailed analysis of the student survey results is included in chart 1.

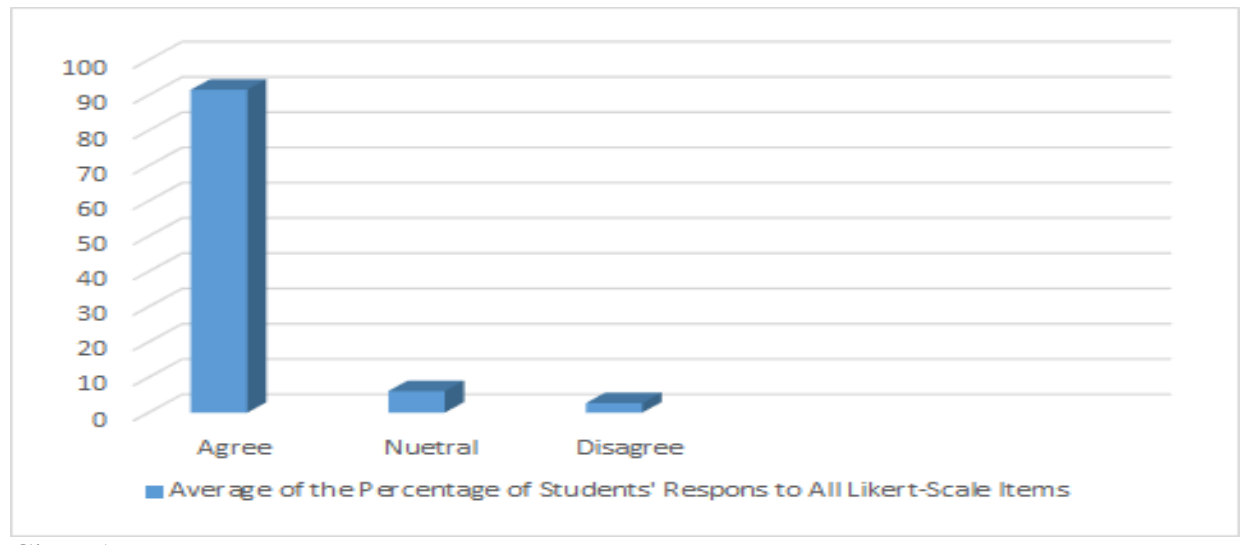

Chart 1

Students' perception of flipped classroom 
In summary, the analysis carried out reflects that the students who made up the sample responded positively to the initiative to implement the flipped classroom and appreciated its potential to promote learning.

The above chart and table 1 demonstrate the average percentage of students' responses to the three-point Likert scale statements. Thus, the majority of the participants $(91.6 \%)$ who were exposed to the flipped classroom intervention expressed positive attitudes towards the effect of employing flipped classroom on their academic performance in science class, while $6.1 \%$ felt neutral and $2.7 \%$ disagreed with the Likert scale questions.

$5 \%$ of the participants would not appreciate flipped instruction learning method more than traditional instruction. And the same percentage $(5 \%)$ felt that the flipped classroom was less engaging and didn't facilitate interaction more than a typical, traditionally instructed classroom.

Moreover, the level of agreement regarding the perceptions about "Appreciating flipped instruction learning method more than traditional instruction" was reflected by $95 \%$ of the participants. This specific finding shows an alignment with several previous studies that declared that students have positive attitudes towards flipped classroom and prefer it to traditional methods. Studies by Willey and Gardner (2013), Davies, Dean, and Ball (2013) and Gaughan (2014) showed that between 73 and 80\% participants were engaged in meaningful and enjoyable activities which was more than typical traditional classes.

To assess perceived flipped classroom benefits as "Making the learning process easier and more motivating", participants rated their level of agreement and appreciation to the maximum $(100 \%)$. In that sense, the derived findings of this research show similarities with the studies done by Karadag \& Keskin, (2017), Mok (2014) and Wilson (2013) in terms of making learning easier, more fun and leading to more understanding and better learning.

For the above-mentioned reasons, the study's analysis reflects that the participants of this study responded positively to the fact that flipped classrooms have the potential to increase the quality of the learning experience.

\section{CONCLUSIONS}

The following conclusions are made from this study:

- There is a connection between flipped classroom instruction and students' learning. The flipped classroom instruction demonstrates a critical, positive and direct impact on students' learning adequacy.

- Developing the longing for active learning in students is one of the critical elements for advancing an effective flipped learning technique. More and more educational institutions are steadily embracing the educator/student instructive relationship change, which will eventually lead to the improvement of existing educational modules. 
- Data generated from this study suggests that the flipped classroom strategy had excessive impact on academic gains. These results were consistent with results from several studies which have reported a significant increase in student learning outcomes using a flipped classroom method, such as (Eichler \& Peeples, 2016; Gillispie, 2016; Wilson, 2013). However, these results are in contrast to other studies which suggested that the flipped classroom instruction had no measurable impact on academic gains (McLean, Attardi, Faden, \& Goldszmidt, 2016 \& Smallhorn, 2017).

\section{RECOMMENDATIONS}

The study makes the following recommendations from the findings:

- Future research exploring different aspects of a flipped instruction application is still strongly needed to establish the student-centered pedagogy of flipped strategy in teaching science and other subject areas. The study recommends future work on flipped instruction with different academic levels and larger samples for educational implications.

- An interesting research project would be to investigate whether the flipped classroom instruction leads to long-term improvement in students' conceptual understanding as suggested by Adams, Garcia and Traustadóttir (2016). For future research, a study can be designed so that a traditional setting of teaching is used during the first half of the semester, while the other half is entirely flipped; the study would use the same set of students, as suggested by Willey \& Gardner (2013).

- The study findings encourage teachers to deal with the integration of technology as a core part of lesson planning. Teachers of science are also encouraged to teach students by using current teaching strategies, in particular, flipped classroom strategy, as it enhances the academic performance of students.

- Pre-service teachers at faculties of education are advised to have suitable training to use new teaching strategies such as flipped classroom. Schools should provide a professional development course for the teachers and students before applying the flipped classroom instruction.

- Schools should be equipped with suitable technology tools, up-to-date laboratory devices, and a reliable high-speed internet service, to help teachers to suggest and implement the required materials in accordance with flipped classroom instruction.

- The accomplishment of a flipped classroom is firmly identified with students' attitudes on learning, and instructors ought to give more chances to students to customize their learning, as well as to support excitement about learning.

\section{RESEARCH LIMITATIONS}

The absence of a random selection was a limitation of the study. The school has only 39 sixth-grade students. A larger number of students would have given the researcher the opportunity of a random selection of the research sample. Another limitation was that 
the gender of the students could have possibly affected the outcomes of the study. Flipped learning had to be applied in one section and traditional learning in the other.

\section{ACKNOWLEDGEMENTS}

The researchers would like to extend a special acknowledgment to Suzanne Kamal Charanek, Mais Elias and Ziad Muktesh for their contribution towards the data collection component of the research, which helped support the overall manuscript. Your time and efforts are greatly appreciated.

\section{REFERENCES}

Abeysekera L. and Dawson P., (2015), Motivation and cognitive load in the flipped classroom: definition, rationale and a call for research, High. Educ. Res. Dev., 34, 1-14.

Adams, A., Garcia, J., \& Traustadóttir, T. (2016). A quasi experiment to determine the effectiveness of a "partially flipped" versus "fully flipped" undergraduate class in genetics and evolution. CBE Life Sciences Education, 15(2). DOI: 10.1187/cbe.15-070157

Ayçiçek, B., \& Yanpar Yelken, T. (2018). The effect of Flipped Classroom Model on students' classroom engagement in teaching English. International Journal of Instruction, 11(2), 385-398. https://doi.org/10.12973/iji.2018.11226a.

Bergmann, J. \& Sams, A. (2012). Flip Your Classroom: Reach Every Student in Every Class Every Day (pp. 120-190). Washington DC: International Society for Technology in Education. Washington, DC: International Society for Technology in Education.

Bishop, J. L., \& Verleger, M. A. (2013, June). The flipped classroom: A survey of the research. In ASEE National Conference Proceedings, Atlanta, GA Vol. 30, No. 9, pp. $1-18$.

Cab1, E. (2018). The Impact of the Flipped Classroom Model on Students' Academic Achievement. International Review of Research in Open and Distributed Learning, 19(3), 202-221.

Chuang, H.-H., Weng, C.-Y., \& Chen, C.-H. (2018). Which students benefit most from a flipped classroom approach to language learning? Flipped classroom does not fit all students. British Journal of Educational Technology, 49(1), 56-68. doi:10.1111/bjet.12530

Clark, D. J. (2015). Automaticity of walking: functional significance, mechanisms, measurement and rehabilitation strategies. Front. Hum. Neurosci. 9:246

Davies, R. S., Dean, D. L., \& Ball, N. (2013). Flipping the classroom and instructional technology integration in a college-level information systems spreadsheet course. Educational Technolo gy Research and Development, 61, 563-580

Duerdan, D. (2013). Disadvantages of a Flipped Classroom. http://www.360edu.com/commentary/disadvantagesof-a-flipped-classroom.htm\#.UtaQkvRdUpW.

Erişim tarihi, 12 Eylül 2016. 
Eichler, J., \& Peeples, J. (2016). Flipped classroom modules for large enrollment general chemistry courses: a low barrier approach to increase active learning and improve student grades. Chemistry Education Research and Practice, 17(1), 197-208.

Elian, S. M., \& Hamaidi, D. A. H. (2018). The Effect of Using Flipped Classroom Strategy on the Academic Achievement of Fourth Grade Students in Jordan. International Journal of Emerging Technologies in Learning (iJET), 13(02), 110-125.

Eryilmaz, M., \& Cigdemoglu, C. (2019). Individual flipped learning and cooperative flipped learning: their effects on students' performance, social, and computer anxiety. Interactive Learning Environments, 27(4), 432-442.

Gaughan, J. E. (2014). The flipped classroom in world history. History Teacher, 47, 221-244

Gecer, A. \& Dag, F. (2012). A blended learning experience. Ed11catiollal Sciences: lher)ly \&Practice, 12 ( I), 438-442.

Gillispie, V. (2016). Using the flipped classroom to bridge the gap to generation Y. Ochsner Journal, 16(1), 32-36.

Girmen, P., \& Kaya, M. F. (2019). Using the Flipped Classroom Model in the Development of Basic Language Skills and Enriching Activities: Digital Stories and Games. International Journal of Instruction, 12(1), 555-572. https://doi.org/10.29333/IJI.2019.12136A

Goedhart, N.S., Blignaut-van Westrhenen, N., Moser, C. \& Zweekhorst, M.B.M. (2019). The flipped classroom: supporting a diverse group of students in their learning. Learning Environments Research, 22(2), 297-310.

Hamdan, N., McKnight, P., McKnight, K. and Arfstrom, K.M. (2013) A review of flipped learning. Pearson Education Limited.

Herreid, C., \& Schiller, N. (2013). Case Studies and the Flipped Classroom. Journal of College Science Teaching, 42, 62-66.

Hew, K. F., \& Lo, C. K. (2018). Flipped classroom improves student learning in health professions education: a meta-analysis. BMC Medical Education, 18, 38. doi:10.1186/s12909-018-1144-z

Hung, H.-T. (2017). The integration of a student response system in flipped classrooms. Language Learning \& Technology, 2l(1), 16-27. Retrieved from http://llt.msu.edu/issues/february2017/hung.pd

Jungić, V., Kaur, H., Mulholland, J., \& Xin, C. (2015). On flipping the classroom in large first-year calculus courses. International Journal of Mathematical Education in Science and Technology, 46(4), 508-520.

Kara, C.O. (2016). Can flipped classroom model be used in clinical education program of medical faculty? Master Thesis. Akdeniz University, Health Sciences Institute, Antalya. 
Karadag, R. \& Keskin, S. S. (2017). The effects of flipped learning approach on the academic achievement and attitudes of the students. NewTrends and Issues Proceedings on Humanities and Social Sciences. [Online]. 4(6), 158-168

Khan, S. (2011, March). Salman Khan: Let's use video to reinvent education. Video on TED.com. TED: Ideas worth spreading, Retrieved April 27, 2017.

Lage, M. J., Platt, G. J., \& Treglia, M. (2000). Inverting the Classroom: A Gateway to Creating an Inclusive Learning Environment. The Journal of Economic Education, 31, $30-43$.

McCallum, S., Schultz, J., Sellke, K., \& Spartz, .J. (2015). An examination of the flipped classroom approach on college student academic involvement. h1temational Journal rd'J'eachil $1 \mathrm{~g}$ and Learning il1 Higher Education, 27(1), 42-55

McLean, S., Attardi, S., Faden, L., \& Goldszmidt, M. (2016). Flipped classrooms and student learning: not just surface gains. Advances in Physiology Education, 40(1), 47 55 .

McLeod, S. A. (2011). Bandura-social learning theory. Retrieved from www.simplypsychology.org/bandura.html. valid scoping review. The Internet and Higher Education, 25, 85-95.

Miller, A. (2012). Five best practices for the flipped classroom. Edutopia, 24, 02-12.

Mok, H. N. (2014). Teaching tip: the flipped classroom. Journal of Information Systems Education, 25(1), 7-11

Nam, H. (2019). The Effect of Flipped Learning Using Multimedia on Learners' Academic Achievement, Intercultural Competence, and Autonomy. Multimedia-Assisted Language Learning, 22(3), 84-101.

O'Flaherty, J., \& Phillips, C. (2015). The use of flipped classrooms in higher education: A scoping review. Internet and Higher Education, 25, 85-95.

Phillips, C.R., \& Trainor, J.E. (2014). Millennial students and the flipped classroom. Journal of Business \& Educational Leadership, 5(1), 102-112.

Pierce, R., \& Fox, J. (2012). Vodcasts and active-learning exercises in a "flipped classroom" model of a renal pharmacotherapy module. American journal of pharmaceutical education, 76(10), 196.

Popham, W. J. (2014). Classroom assessment: What teachers need to know (Seventh edition ed.). New Jersey: Pearson Education.

Quint, C. L. (2015). A study of the efficacy of the flipped classroom model in a university mathematics class (Order No. 3707108). Available from ProQuest Dissertations \& Theses Global. 1695832181). Retrieved from http://search.proquest.com/docview/1695832181 accountid=62373 
Ryan, M. D., \& Reid, S. A. (2015). Impact of the flipped classroom on student performance and retention: A parallel controlled study in general chemistry. Journal of Chemical Education, 93(1), 13-23.

Schreiber, L. M., \& Valle, B. E. (2013). Social constructivist teaching strategies in the small group classroom. Small Group Research, 44(4), 395-411.

Schultz, D., Duffield, S., Rasmussen, S., \& Wageman, J. (2014). Effects of the flipped classroom model on student perfonnance for advanced placement high school chemistry students. Journal l? \{ Chemical Engineering, 91(9), 1334-1339.

Shana, Z. (2009). A Pilot Study to Investigate the Effectiveness of Multimedia CDROM Vis-À-Vis Traditional Print-Based Technology in Teaching Fourth-Grade.

Shana, Z., \& Abd Albaki, S. (2020). Using Plickers in Formative Assessment to Augment Student Learning. International Journal of Mobile and Blended Learning (IJMBL), 12(2), 57-76.

Smallhorn, M. (2017). The flipped classroom: A learning model to increase student engagement not academic achievement. Student Success, 8(2), 43-53.

Strayer, J. (2007). The effects of the classroom flip on the learning environment: A comparison of learning activity in a traditional classroom and a flip classroom that used an intelligent tutoring system. Doctoral dissertation, The Ohio State University.

Wang, K., \& Zhu, C. (2019). MOOC-based flipped learning in higher education: students' participation, experience and learning performance. International Journal of Educational Technology in Higher Education, 16(1), 1-18.

Willey, K., Gardner, A. (2013). Flipping your classroom without flipping out. 41st European Society for Engineering Education Conference (SEFI 2013), Leuven: European Society for Engineering Education.

Williams, B. (2013). How I flipped my classroom. Presented at the National Neonatal Nurses Conference Summer Technology Institute, Norfolk, NE.

Wilson, S. (2013). The flipped class: A method to address the challenges of an undergraduate statistics course. Teaching of Psychology, 40(3), 193-199.

Wolff, LC, Chan, J. (2016). Flipped classrooms for legal education. Singapore: Springer Verlag. 